\title{
A Good Workman Never Blames His Tools: Appropriate Use of Severity of Illness Scoring Systems Determines Their Utility!
}

\author{
Soonu Udani
}

\begin{abstract}
Scoring systems in intensive care units allow assessment of the severity of disease and predicting mortality. They also help in allocation of resources and benchmarking performance when compared to other units and hence to development of skills within a unit. Their use needs to go beyond just mortality prediction and unit statistics. The data collected are useful for resource allocation, unit audits, comparison with local units as well as for quality improvement programs and education.

Keywords: PELOD 2, PICU mortality, Quality improvement.

Indian Journal of Critical Care Medicine (2020): 10.5005/jp-journals-10071-23545
\end{abstract}

Scoring systems in the intensive care units (ICUs) allow assessment of the severity of disease and predicting mortality. They also help in allocation of resources and benchmarking performance when compared to other units and hence to development of skills within a unit. Several scores are used with good correlation and validity. The choice often lies in ease of calculation and applicability and the number of parameters required for the scoring system. Geographical preferences also play a role. The pediatric logistic organ dysfunction scoring system (PELOD) score was developed in France in $1999^{1}$ and updated to PELOD 2 in 2013 by the original authors ${ }^{2}$ and is popular there, and the Pediatric Index of Mortality2 $(P I M 2)^{3}$ was devised by Shann's group in Australia and is used in that subcontinent. Pediatric risk of mortality (PRISM) $\mathrm{III}^{4}$ is probably the most cumbersome but widely used, especially in the American subcontinent.

It is highly unlikely that today a child will die in a pediatric ICU (PICU) without ventilation or inotropes and usually with both. Hence to say that intubated patients have a higher mortality is really irrelevant. What is more startling is the high mortality (17/23 i.e., $74 \%)$ reported by Deshmukh et al. in this issue of the journal. ${ }^{5}$ This appears far too high by any standard. As ventilation itself gives a high score on the PELOD, these children would certainly have a higher score.

"Hematological illness had highest mortality" is a loose statement the authors make, as hematalogical could mean anything

Table 1: Various scores calculated on admission to PICU 6

\begin{tabular}{|c|c|c|c|c|c|c|}
\hline & Outcome & Mean & $S D$ & $95 \% \mathrm{Cl}$ & $p$ value & $A U C$ \\
\hline \multirow[t]{2}{*}{ PRISM III } & Died & 12.9 & \pm 9.27 & $10.55-15.24$ & $p<0.0001$ & 0.751 \\
\hline & Survived & 5.73 & \pm 4.86 & $5.00-6.46$ & & \\
\hline \multirow[t]{2}{*}{ PIM2 } & Died & 0.22 & \pm 0.29 & $0.15-0.3$ & $p<0.0001$ & 0.747 \\
\hline & Survived & 0.06 & \pm 0.10 & $0.04-0.07$ & & \\
\hline \multirow[t]{2}{*}{ PEMOD } & Died & 7.05 & \pm 3.88 & $6.07-8.03$ & $p<0.0001$ & 0.732 \\
\hline & Survived & 4.13 & \pm 2.82 & $3.70-4.55$ & & \\
\hline \multirow[t]{2}{*}{ PELOD } & Died & 15.17 & \pm 14.25 & $11.56-18.77$ & $p<0.0001$ & 0.762 \\
\hline & Survived & 4.96 & \pm 8.31 & $3.71-6.20$ & & \\
\hline \multirow[t]{2}{*}{ SOFA } & Died & 10.55 & \pm 4.50 & $9.41-11.69$ & $p<0.0001$ & 0.765 \\
\hline & Survived & 6.34 & \pm 3.47 & $5.82-6.86$ & & \\
\hline
\end{tabular}

AUC, area under the curve; PELOD, pediatric logistic organ dysfunction scoring system; PEMOD, pediatric multiple organ dysfunction scoring system; PIM2, revised pediatric index of mortality score; PRISM III, pediatric risk of mortality score; SOFA, sepsis-related organ failure assessment; TISS, therapeutic intervention scoring system

() The Author(s). 2020 Open Access This article is distributed under the terms of the Creative Commons Attribution 4.0 International License (https://creativecommons. org/licenses/by-nc/4.0/), which permits unrestricted use, distribution, and non-commercial reproduction in any medium, provided you give appropriate credit to the original author(s) and the source, provide a link to the Creative Commons license, and indicate if changes were made. The Creative Commons Public Domain Dedication waiver (http://creativecommons.org/publicdomain/zero/1.0/) applies to the data made available in this article, unless otherwise stated. 
In this comparison of five scoring systems ${ }^{6}$ (Table 1), where score for each patient was calculated on all scoring systems, it was seen that there was very good correlation among all different systems used. Hence, it probably matters very little what system is used in a unit. What matters is how its interpreted and what the unit does with the data.

Using it as a quality improvement tool internally or by comparing its data with that of similar units nationally and internationally would be important. Predicting mortality as an end point in itself has very little meaning. We neither counsel the family based on the score and nor should we allow the score to guide our attitude toward further management lest a poor prognostic score should lead to a laxity in attitude and a selffulfilling prophesy. This study would therefore have had greater meaning had it defined to what purpose the scoring was being done, as simple validation of the PELOD 2 score adds no new finding to the literature.

In conclusion, in PICUs in India, we should use standard scoring systems and preferably we should, as a body, agree upon one system so that we can pool and compare data and use the data for research and quality improvement.

\section{References}

1. Leteurtre S, Martinot A, Duhamel A, Gauvin F, Grandbastien B, Nam TV, et al. Pediatric logistic organ dysfunction (PELOD) development of a pediatric multiple organ dysfunction score: use of two strategies. Med Decis Making 1999;19(4):399-410. DOI: 10.1177/0272989X 9901900408.

2. Leteurtre S, Duhame A, Salleron J, Grandbastien B, Lacroix J, Leclerc $F$, et al. PELOD-2: an update of the pediatric logistic organ dysfunction score. Crit Care Med 2013;41(7):1761-1773. DOI: 10.1097/ CCM.0b013e31828a2bbd.

3. Slater A, Shann F, Pearson G, Paediatric Index of Mortality (PIM) Study Group. PIM2: a revised version of the pediatric index of mortality(PIM2). Intensive Care Med 2003;29(2):278-285. DOI: 10.1007/ s00134-002-1601-2.

4. Pollack MM, Patel KM, Ruttimann UE. PRISM III: an updated pediatric risk of mortality score. Crit Care Med 1996;24(5):743-752. DOI: 10.1097/00003246-199605000-00004.

5. Deshmukh T, Varma A, Damke S, Meshram R. Use of PELOD 2 score in predicting mortality and morbidity in patients admitted in PICU. Indian J Crit Care Med 2020;24(8):701-704.

6. Rady HI, Mohamed SA, Mohssen NA, Elbaz M. Application of different scoring systems and their value in pediatric intensive care unit. Egypt Paediatr Assoc Gaz 2014;62:59-64. DOI: 10.1016/j.epag.2014.10.003. 